\title{
The Complementary Roles of Laboratory Notebooks and Laboratory Reports
}

John B. McCormack, Member, IEEE, Robert K. Morrow, Jr., Member, IEEE, Harold F. Bare, Senior Member, IEEE, Robert J. Burns, Member, IEEE, and James L. Rasmussen, Member, IEEE

\begin{abstract}
Experiments can be documented by the complementary use of both laboratory notebooks and laboratory reports. The notebook serves as a chronological repository for experimental details, while the report presents a logical summary of the experiment. Emphasis on proper format and logical content in both notebooks and reports encourages the successful development of technical writing skills. When properly used, laboratory notebooks and laboratory reports interact to improve the quality of both. This paper outlines the contents of laboratory notebooks and laboratory reports, and explains how the complementary use of these instruments at the Air Force Academy has resulted in better student writing, better design documentation, and more efficient use of laboratory and computer resources that should carry over into future engineering practice.
\end{abstract}

\section{INTRODUCTION}

L ABORATORY notebooks and laboratory reports have distinct, complementary roles in both industry and academia. Both documents facilitate technical communications, but they serve different purposes and accomplish different goals.

Notebooks are used to record the process of scientific discovery, the evolution of a project, design rationale, and the steps in engineering analysis. In the notebook, the experimenter records the procedures followed, the raw data collected, and any ideas or observations as they occur.

Reports, on the other hand, logically summarize the work accomplished in the laboratory. In a laboratory report, the researcher presents the observations and discoveries documented in the notebook. The laboratory notebook should substantiate the laboratory report, but it is not a suitable substitute for a well-written report. In this paper, we explain how we restructured electrical engineering laboratory documentation at the Air Force Academy to better emphasize the interaction of laboratory notebooks and laboratory reports, and we discuss the corresponding improvement in the quality of learning that resulted.

\section{BACKGROUND}

Until recently, laboratory course work in the Department of Electrical Engineering at the Air Force Academy was documented almost exclusively in laboratory notebooks. Students completed much of their reports in their notebooks prior to the laboratory exercise by listing procedure steps, constructing data tables, and leaving space for recording observations. Entries were made in ink with mistakes neatly lined through. Once this prelab report was graded, they proceeded with the exercise.

Several observations led us to question the effectiveness of this approach. We were asking our students to write a laboratory report between the covers of a laboratory notebook, and

Manuscript received October 24, 1990.

The authors are with the Department of Electrical Engineering, U. S. Air Force Academy, Colorado Springs, CO 80840.

IEEE Log Number 9041396. preventing them from using the notebook to properly document their progress. In particular, we observed poorly documented designs, marginal student writing skills, and underutilized computer resources.

We noticed that many students kept several notebooks: one in which they scribbled their data, and another into which they transcribed the data to be submitted for a grade. Other students kept their laboratory notes on loose scraps of paper before transcribing their data. By assigning grades based on the quality of what was in the notebook, we defeated one of the principal purposes of keeping laboratory notes, which is to accurately document what was being done. A design may have gone through several iterations, but only the final, successful design was documented in the notebook/report.

We observed that some of our students were poor technical writers. Clearly, if we wanted our students to write better, we had to give them an opportunity to learn. Laboratory documentation seemed like an excellent place to start. By grading what were essentially first draft efforts from their laboratory notebooks, we were not giving our students a chance to hone their writing skills.

We realized that we were not letting our students exploit available computer resources. Each student owned an IBM-AT compatible computer, each student had the same battery of software, and each student's computer was tied to a local area network with over 50 laser printers. Why were we asking them to write their reports in longhand? Handwritten reports were not in step with the times.

Available literature convinced us that laboratory reports and laboratory notebooks serve different purposes. By trying to combine the two instruments into a single product, we were achieving neither goal. In the Spring of 1989 , we introduced new documentation guidelines in three laboratory courses. The results of this experiment were dramatic. The students responded enthusiastically, their writing got better, the quality of their design and depth of analysis improved, and they began using their computers more for analysis and design as a byproduct of using them for composition.

The following section describes what we think should be in a laboratory notebook, and the subsequent section describes our laboratory reports. The final section explains how we blended the use of laboratory notebooks and word processed reports to obtain better results than we observed with the hybrid notebook/ report used in the past.

\section{NoTEBOOKS}

In engineering practice, one of the principal reasons for keeping a laboratory notebook is to create legally admissible evidence [1], [2]. Laboratory notebooks are frequently used in 
patent claims. The notebook can document compliance with approved test procedures, contract provisions, safety standards, or environmental protection requirements. A student should be required to follow the same guidelines as a professional in keeping laboratory notes for two reasons: to learn and practice good notekeeping, and to compile complete and accurate data for use in the laboratory report.

\section{Notebook Mechanics}

Because of legal requirements, the format of a laboratory notebook is rigidly defined [3]. Notebooks must be bound, and consist of sequentially numbered pages. All entries must be made sequentially in indelible ink, and must be signed, dated, and witnessed. Dates should be unambiguous i.e., 9 May 1988 rather than 5/9/88. Errors must not be obliterated, but crossed out with a single line. Any alterations or pasted in material must also be signed and dated. Unused space must be marked through with an " $\mathrm{X}$ " or " $\mathrm{Z}$ "' to ensure that material is not added later.

In Writing the Laboratory Notebook, $\mathrm{H}$. Kanare detailed the best types of paper, adhesives, and inks to use to record laboratory notes; how to properly issue and store notebooks; and how to properly witness notebook contents [3]. It is sufficient that student notebooks conform to the seven requirements outlined above, but students should still be aware of other specifications.

\section{Notebook Contents}

When a patent lawyer was asked what should be included in a laboratory notebook, the reply was "everything." We expanded "everything" into a detailed list of notebook contents, patterned on the familiar list of five $W$ 's used by newspaper reporters. Some of the items that should be included in a laboratory notebook are listed below [1]-[3]. The asterisked items are required in our courses.

1) Who
* a) Experimenters
b) Sponsors
c) Witnesses
2) What
* a) Brainstorm possible solutions
* b) Experimental design
* c) Results: samples, raw data
* d) Analysis of data
* e) Conclusions to be drawn
* f) Difficulties encountered
* g) False starts, wrong turns and blind alleys

3) When
a) Projected completion date and milestones
b) Explanation of delays (supply backlog, etc.)

* c) Record of progress

4) Where
a) Location of equipment
b) Location of models, samples, etc.
c) Address of author

5) Why

* a) Statement of problem

b) Authorization (cite funding sources)

* c) Rationale for engineering decisions and the design of the experiment
6) How

* a) Equipment used

i) Model numbers

ii) Calibration date

* b) Set up diagrams

* c) Procedure followed

* d) Flow charts

e) Photographs

\section{Notebook Style}

Writing is meant to be read. Attention to notebook style not only makes it easier for another engineer to follow the project's progress, but helps the author reconstruct the laboratory experience for the laboratory report.

The biggest obstacle facing the notetaker is the immutable chronological order of the notes. In a proper laboratory notebook all notes are taken in ink, in a bound book with sequentially numbered pages. Experimenters do not have the luxury to reorder their thoughts, or to streamline their prose on a second or third writing. What gets recorded on Monday cannot be changed on Tuesday. That, unfortunately, is the nature of a laboratory notebook. Therefore, some attention must be paid to the style of the notes as they are entered, so that when the hour comes (perhaps years from the original entry) to write a doctoral dissertation, to produce a technical report, or to present a patent claim, the original work can be adequately reconstructed. Since it is nearly impossible to maintain logical organization in a chronological notebook, Hughson suggested that new material be cross referenced to previous entries [1].

Notebook front matter includes the book title, table of contents, and preface [3]. The title should be descriptive enough to identify a particular laboratory book from a stack of similar looking notebooks. The table of contents should have enough information about the contents to be useful, but should not contain so much that it is hard to read. The preface does not have to be long, but it should identify the author, the goal of the project, and a summary of the progress to date.

Every notebook will be as unique as its author, but the glue that holds it together is its organization. In our courses we use an outline suggested by Kanare [3]:

1) Background

2) Planning

3) Execution

4) Study of Results

If a more detailed outline is required, it could include the headings planned for the final report, or follow the steps in the engineering method as described by Eide [4].

\section{Notebook Evaluation}

Since the laboratory notebook could be the deciding factor in winning or losing a patent suit, the experimenter's superiors have a vested interest in its contents. Proper grammar, style, and handwriting will certainly make the notes more readable, but the most important thing to a supervisor is that the notebook conforms to legal guidelines, and that it contains, as that patent lawyer said, "everything."

The same criteria should hold for evaluating a laboratory notebook in a college course. A heated debate raged in the pages of The Journal of Chemical Education in the 1920's and 1930's over the proper way to evaluate laboratory notebooks [5]-[8]. The consensus was best stated by Bowers, who quoted an ear- 
lier article by Rowell: “. . a science notebook is a great factor in education if it is a means to an end . . . as a tool, it is priceless, as a product it is worthless.', [5]. There was a general agreement that a notebook is properly used as a tool to document work, but should not stand alone as a vehicle for communicating results.

Laboratory notes should be complete; the manner in which an experiment was organized and conducted is valuable information. Stubbs dissented on the value of writing complete reports [8]. He asserted that writing did not help students remember important concepts, and he objected to the tedious copying of printed instructions into a notebook. What he overlooked was that, in properly written laboratory notes, the experimenter will write down the procedure steps as they are accomplished so that the notebook provides evidence of missed procedure steps or deviation from the proper sequence of steps that may corrupt the data.

Gould and Mortensen agreed that laboratory notebooks should be graded daily, in the laboratory [6], [7]. In the workplace, supervisors review their subordinate's laboratory notes frequently to ensure that data and observations are recorded properly, and that work is progressing as expected. By evaluating student notebooks daily, the instructor can likewise track the students' progress and provide immediate feedback.

Kanare provided a ten-point supervisor's checklist that, excepting items 9) and 10), works admirably in the classroom [3]:

1) Are notes written in black ball-point pen?

2) Is the handwriting legible? Are the numbers and symbols unambiguous?

3) Is the table of contents up-to-date?

4) Is each entry signed and dated unambiguously?

5) Does each section have a clear, grammatical heading that describes the work reported therein?

6) Are the entries written in the first person telling who did the work?

7) Is the work described completely so that it can be understood without additional explanation by the writer?

8) Is the researcher "thinking in the notebook?" That is to say, are ideas and observations entered immediately and directly into the book and not on scraps of paper that are transcribed later?

9) Are entries witnessed correctly?

10) Is the notebook stored safely when not in use?

\section{Summary}

There are rigidly defined guidelines for creating laboratory notes, primarily because of lessons learned through litigation. Laboratory notebooks, most importantly, must document who did what, and when, where, and how was it done. There should be no ambiguity or question of authenticity. When students learn to take adequate laboratory notes in school, they will have fewer troubles taking adequate notes in industry where poor documentation carries a much higher cost.

\section{REPORTS}

The one product of experimentation that others will usually see is the report. In a university course, the laboratory report documents the student's experience and level of understanding. Writing the report enhances the communication skills the student will need to be a successful engineer. Beyond the classroom, reports can take many forms, such as patent applications, technical papers, operating instructions, or fabrication specifications.

Laboratory reports are gleaned from the laboratory notebooks. Any information needed to prepare a report should be contained in the notes made as the project progressed. The more information contained in a laboratory notebook, the less the author must dig to write an interim or final report [1].

One key to good writing is revision. Strunk and White observed that even the best authors need to revise and rewrite their work [10]. The importance of revision is the main reason that laboratory notebooks should not substitute for a summary report, even in an academic environment. Gwiasda pointed out that revision is an iterative process, and one that is often ignored in student writing [11]. Students should be given every opportunity to hone their technical writing skills since, as Michaelson observed, "organizing results into formal, written communication gives the engineer a better understanding of the work reported"' [9]. Katz and Warner reported that requiring good writing as a part of good engineering resulted in better organization, improved critical thinking skills, and more student confidence [12].

\section{Report Mechanics}

Since virtually all students have access to a word processor, there is scant justification for any other method of preparing a laboratory report. V. Arms asserted that word processing frees the writer to concentrate on content rather than mechanics [13]. The engineering student should be comfortable with word processing since it is rapidly becoming the standard in engineering practice.

Despite the miracle of word processing, the novice may need to put in a lot of time and effort to prepare a laboratory report. Enter the word processor (again). In a university course, instructors can provide students the shell of a laboratory report, either via floppy diskette or over a local area network. The shell will conform to the style that the instructor wants, and the amount of information can be expanded or contracted as requirements dictate. The shell for an initial laboratory report in an introductory laboratory course may be up to $50 \%$ complete, with theory explained, and figures and tables already arranged for the student. Shells for reports required in later courses would have progressively less material, and require the bulk of the report to be created by the student.

\section{Report Contents}

There are many texts that explain how to write technical reports [14]-[16]. Although these books vary slightly, they generally agree that a laboratory report should contain the following elements:
1) Summary (similar to an abstract)
2) Statement of the Problem
3) Apparatus
4) Procedure
5) Test Results
6) Analysis
7) Conclusions
8) References

A student report should conform to the format specified by the text used in the curriculum. A report prepared for publication must conform to the format specified by the publisher. 


\section{Report Style}

Good technical writing is good writing. A technical report must be precise, and so must the prose. For instance, one writer may report that a set of measured data was a "pretty good match" to that predicted. A better writer will state that the data had a correlation coefficient of 0.989 .

Technical reports make greater use of figures, tables, and graphs than other types of reports. Consequently, strict attention must be paid to graphic design and layout. Although the content of a technical report may be complicated, the style should be simple. A good technical writer uses simple sentences and simple words, remembering that the goal of writing the paper is to communicate.

Good writers know their audience. Audiences, according to Pauley and Riorden, have four characteristics: a level of knowledge, a need for the report information as either user or decision maker, an organizational relationship to the writer, and an emotional predisposition to react positively or negatively to the report [15]. Although an engineer's goal in writing is to communicate needed information to other engineers, Gwiasda observed that students usually learn to write laboratory reports for a very narrow audience: an instructor who already knows the material better than they do [11]. Student writers can progress beyond this academic pitfall by consciously analyzing their audience before they begin writing. We tell students in introductory courses to aim their reports at other students taking the course. In upper-division courses however, role playing is more appropriate: we have instructed students to report their results in the style of a technical journal, to generate user manuals, or to create instructional material for underclassmen.

Writing across the curriculum is a recent emphasis at many schools, including the Air Force Academy, to make writing a pervasive part of education in all disciplines. Writing assignments in most courses help students organize their thoughts and employ critical thinking skills [17]. Georgopoulus and Georgopoulus stressed the widening gap between the need for engineers to communicate and the inability of recent graduates to accomplish that task [18]. The Accreditation Board for Engineering and Technology (ABET) expects students to demonstrate competency in written communication through writing done in engineering courses [19]. The conclusion drawn by Georgopoulus and Georgopoulus is that technical writing should be taught by engineering faculty, and that the laboratory report is a good vehicle for accomplishing that task [18]

\section{Report Evaluation}

A laboratory report must be evaluated both on content and composition. Gwiasda observed the tendency for engineering faculty to overlook composition flaws if the paper is technically correct [11]. Katz and Warner also stressed that the technical paper must be evaluated for its writing as well as for its technical content [12]. Good writing results from diligence in preparation. Unless writers are motivated to write well, mediocrity will result.

\section{Summary}

Laboratory reports are written to communicate experimental results to a specific audience. Laboratory report writing can be made less intimidating and time consuming by providing word processor report templates so writers can concentrate on style and grammar and thereby produce more readable and meaningful reports.

\section{SYNERGY OF NOTEBOOKS AND REPORTS}

We introduced the complementary use of laboratory notebooks and laboratory reports on a trial basis in three courses: the sophomore laboratory course, a junior-level microprocessor course, and a senior-level electronics laboratory. The changes were made optional for the seniors, but all the students chose to follow the new procedures.

Our first task was to teach the students to follow the expected notebook practices. We did this by grading their notebooks daily, not on the quality of the work, but upon whether they were using the notebook as intended. After reviewing their work, we signed the witness block on the bottom of the notebook page. We forbade them to carry any other papers into the laboratory. The quality of the notebook work improved dramatically when the students realized that their notebooks were not being graded as reports, but rather as tools used to record their work. Since they received feedback daily rather than five or six times over the semester, they were more motivated to show progress every lesson.

Our next task was to generate word processing templates for the laboratory reports. We composed one shell for each laboratory exercise. This task was not as imposing as it first seemed. A template can be created in an hour or two from a generic outline and the student laboratory handout. The first report of the sophomore course was written almost entirely for the student. The results were omitted, and empty tables and graphs were included for students to complete. Report shells for subsequent laboratory exercises conformed to the same outline, but emphasized different aspects of report writing. The second shell required the students to focus on writing a good summary, the next required the students to concentrate on enumerating procedures. The format complied with the Modern Language Association (MLA) handbook [20], which is the standard for the entire school. Document files created in Microsoft Word were loaded into a directory on our local area network. The students were instructed to download this file so they could edit it and print their reports using the network laser printers. These reports were graded equally on technical writing and on engineering content.

The results of this experiment were so encouraging that every electrical engineering laboratory course will conform to the guidelines in the future. The students enthusiastically supported the revised laboratory documentation procedures. They typically put slightly more time into accomplishing the laboratory work, but they were learning much more, and enjoying it. In addition to keeping better notebooks and writing better reports, students started using the computer as an analysis tool. We noted an increased use of spreadsheets, CAD packages, and graphics programs. By encouraging the complementary use of laboratory notebooks and word processed laboratory reports, we significantly improved the quality of our laboratory program.

\section{CONCLUSION}

Our experience at the Air Force Academy has taught us the benefits that can be experienced by the complementary use of laboratory notebooks and laboratory reports. The notebook is written as the work progresses to record the day-to-day evolution of a design. It is the primary documentation of who did what, when, where, and how. The report is a summative instrument used to communicate results to an interested audience. We found that students responded favorably to our revised laboratory documenting practices. They kept better notes, im- 
proved their writing skills, and made better use of computer resources. Our experience showed that notebooks and reports work best when they supplement each other. The complementary use of notebooks and reports result in more productive students, who we fully expect to become more productive engineers.

\section{REFERENCES}

[1] R. V. Hughson, "The right way to keep laboratory notebooks," IEEE Trans. Prof. Comm., vol. PC-22, no. 2, pp. 83-85, June 1979.

[2] W. G. Konold et al. What Every Engineer Should Know About Patents. New York: Marcel Decker, 1979.

[3] H. M. Kanare, Writing the Laboratory Notebook. Washington, DC: Amer. Chem. Soc., 1985.

[4] A. R. Eide et al. Engineering Fundamentals and Problem Solving, 2nd ed. New York: McGraw Hill, 1986.

[5] W. G. Bowers "Notebooks in laboratory instruction," J. Chem. $E d .$, vol. 3, no. 4, pp. 419-424, Apr. 1926.

[6] H. W. Gould and J. Millikin, "How to grade laboratory notebooks," J. Chem. Ed., vol. 4, no. 7, pp. 890-891, July 1927.

[7] J. C. Mortensen, "How when and where to grade laboratory notebooks," J. Chem. Ed., vol. 4, no. 7, pp. 892-893, July 1927

[8] M. F. Stubbs, "An experimental study of methods for recording laboratory notes in high-school chemistry," J. Chem. Ed., vol. 3, no, 3, pp. 296-300, Mar. 1926.

[9] H. B. Michaelson, "Teaching engineering students to communicate," IEEE Trans. Educ., vol. E-27, pp. 151-154, Aug. 1984

[10] W. Strunk, Jr. and E. B. White, Elements of Style, 3rd ed. New York: Macmillan, 1979.

[11] K. E. Gwiasda, "Classrooms and contexts: Teaching engineer to write wrong," IEEE Trans. Educ., vol. 27, pp. 148-150, Aug. 1984

[12] P. S. Katz and T. E. Warner, "Writing as a tool for learning," IEEE Trans. Educ., vol. 31, pp. 214-216, Aug. 1988.

[13] V. M. Arms, "Engineers like to write-On a computer!", IEEE Trans. Prof. Comm., vol. 26, no. 4, pp. 175-177, Dec. 1983

[14] R. S. Blicq, Technically-Write!, 3rd ed. Englewood Cliffs NJ: Prentice Hall, 1986

[15] S. E. Pauley and D. G. Riorden, Technical Report Writing To day, 3rd ed. Boston: Houghton Mifflin, 1985.

[16] M. T. Turner, Technical Writing, A Practical Approach Reston, VA: Reston, 1984.

[17] C. W. Griffin, Ed. Teaching Writing in All Disciplines. San Francisco: Jossey-Bass, Dec. 1982

[18] C. J. Georgopoulus and V. C. Georgopoulus, "From university term papers to industry technical reports-An attempt to bridge the existing gap," IEEE Trans. Educ., vol. 27, pp. 143-147, Aug. 1984.

[19] Criteria for Accrediting Programs in Engineering in the United States. New York: ABET, 1989.

[20] J. Gibaldi and W. S. Achtert, MLA Handbook, 3rd. New York: Modern Language Association, 1988.

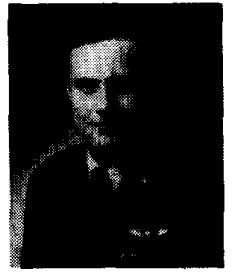

John B. McCormack (S'77-M'79-S'86M'87) received the B.S.E.E degree from the Air Force Academy, Colorado Springs, $\mathrm{CO}$, in 1979 and the M.S.E.E. degree from the Air Force Institute of Technology, Wright-Patterson, $\mathrm{AFB}, \mathrm{OH}$, in 1987.

He has served in the Air Force as a pilot and an electrical engineer at Columbus AFB, MS; Carswell AFB, TX; Andersen AFB, Guam; and Wright-Patterson AFB, OH, prior to teaching at the Air Force Academy. His principal interests are in the areas of low observables, radar cross-section, reliability, and aircraft survivability. He is Assistant Professor of Electrical Engineering at the United States Air Force Academy.

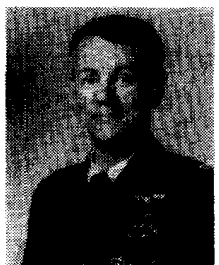

Robert K. Morrow, Jr. (S'86-M'88) was borm in Woodbury, NJ, on June 4, 1952. He received the B.S. degree in electrical engineering from the U.S. Air Force Academy, Colorado Springs, CO, in 1974, the M.S.E.E. degree from Stanford University, Stanford, CA, in 1982, and Ph.D. degree in electrical engineering in 1988 from Purdue University, West Lafayette, IN.

Presently, a Lieutenant Colonel in the U.S. Air Force, he has accrued over 2300 hours of instructor, first pilot, and copilot flying time in four types of military aircraft from 1974 through 1985 . He served on the electrical engineering faculty of the U.S. Air Force Academy from 1982 through 1985, where he taught undergraduate electrical engineering, managed the $\mathrm{Ca}$ det Summer Research Program, and piloted the aircraft used by the cadet parachute team. He recently returned to the USAF Academy faculty as the computer engineering division chief in the Department of Electrical Engineering and presently serves as the Director of Research. His research interests include digital and analog communications and computer engineering.

Dr. Morrow is a life member of the Air Force Association and holds an Advanced Class Amateur Radio license.

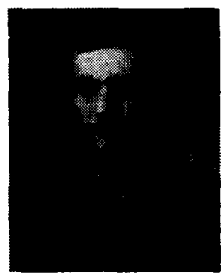

Harold F. Bare (S'68-M'76-SM'88) received the B.S.E.E. degree from the Virginia Military Institute, Lexington, in 1970 , the M.S.E.E. degree from Pennsylvania State University, University Park, in 1972, and the Ph.D. degrees in electrical engineering from Purdue University, West Lafayette, IN, in 1986.

Since entering the U.S. Air Force in 1972 he has worked in the areas of space vehicle instrumentation, electronic warfare, and semiconductor technology development including silicon-on-sapphire and bulk CMOS technologies, integrated circuit fabrication, and amorphous silicon thin film transistors. As an Associate Professor of Electrical Engineering at the U.S. Air Force Academy, he has been involved with curriculum development and improvements to the laboratory program.

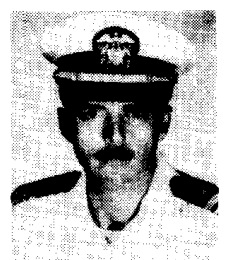

Robert J. Burns (M'89) was born in Saginaw, MI, on July 1, 1949. He received the B.S. de gree in electrical engineering from Marquette University, Milwaukee, WI, in 1976 and the M.S. degree from the University of Illinois, Urbana, in 1986.

His experience during 19 years of Naval service includes: an enlisted avionics technician 1971-1973; NESEP commissioning program 1973-1976; Navy flight training and designation as a Naval Flight Officer 1976-1978; a navigator/ASW tactical coordinator aboard P-3B Orion aircraft, VP-11, NAS Brunswick, ME, 1978-1981; navigation instructor/advisor, NROTC Unit, University of Illinois, Urbana 1981-1985; maintenance/operations specialist with a P-3 operations center at NAS Cub Point, Philippines 1986-1988; and at present, an Assistant Professor of electrical engineering at the U. S. Air Force Academy. His interests are in antennas and scattering measurements, laser technology, fiber optics and nonlinear optical devices.

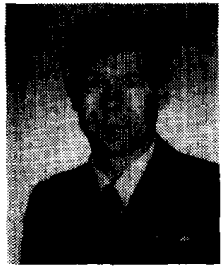

James L. Rasmussen (M'89) received the B.S.E.E. degree from Michigan Technological University, Houghton, in 1979 and the M.S.E.E. degree from Stanford University, Stanford, CA, in 1983.

$\mathrm{He}$ is currently an Assistant Professor of Electrical Engineering at the United States Air Force Academy, Colorado Springs, CO. Since entering the Air Force in 1973, he has served in the areas of radar maintenance, inertial navigation systems maintenance and development, and development of nuclear instrumentation systems. His interests are in the areas of digital signal processing and its uses in measurement and instrumentation systems. 